Madrygal. Revista de Estudios Gallegos

ISSN: 1138-9664

\title{
Moi poucos coma el. Lembrando a Fermín Bouza
}

Vicente Araguas

Teño estado con Fermín Bouza unha chea de veces, desde aqueles días en que o curso 6768 comezaba, en Santiago (onde Fermín nacera, o 5 de marzo de 1946), xeitos e maneiras. Éramos os dous alumnos de Filosofía e Letras (Filosofía e Xesús, dicía Don Carlos Alonso del Real coidando na abondancia de cregos e monxas que naquela Facultade rulaban e -ás veces- rolaban). Fermín viña de Valencia, onde chegara a cuarto curso de Ciencias Físicas; unha das cousas que máis me abraiaban do amigo, que soubera tanto de materias tan abstrusas para min, tamén que non rematara unha carreira tan á man. Diante do meu abraio o Fermín sorría, con aquel sorriso aberto e tenro e retranqueiro que vencello ao seu rostro, tan céltico como o cabelo roxo que lle cubría a nobre cabeza. Fermín moraba nunha casa igualmente dobre, da Rúa do Vilar. Unha morada de dous andares que se comunicaban por unha escaleira de caracol. No fondo, na penumbra, lembro a figura lanzal de Fermín Bouza-Brey, esculcando algún documento con lupa, en todo caso poñendo moi de perto dos ollos os papeis que andaba a manexar. Don Fermín, pai, segue a ser un poeta decisivo na lírica galega. Autor de Nao senlleira e Seitura, o poeta andivera por terreos neopopularistas "avant la lettre", en paralelo (e non despois) con Lorca, Alberti e "tutti quanti" desfolaban a flor máxica da poesía trobadoresca. Mais Bouza-Brey ollaba para nós silandeiro, rompendo o silencio apenas para nos lembrar que non todo era ouro o que relocía nos poetas de tendencia que nós tanto amábamos. Logo, co tempo, ataríamos cabos e actitudes. De momento, aquel curso, a primavera (de París, Berlín, Berkeley, Praga) viría para nós adiantada, a febreiro, en forma dunha folga intensa que mantería a universidade pechada ata abril. Entremedias lembro nidiamente a Fermín, "home múltiple" definírao eu daquela, como actor (nunha montaxe sobre textos de Hemingway chamada Nunca nadie muere nadie), rapsoda (nun acto-homenaxe a Ernesto "Che" Guevara, rebentado por exiliados cubanos, a partir de poemas de José Martí ou Nicolás Guillén), activista político, militante dun partido de esquerdas de orientación "prochina", PC (M-L), do que fun compañeiro de viaxe. Fermín estivera no Paraninfo de Medicina o día no que a policía, arengada polo comisario Armada, irrompera salvaxemente contra quen nos defendíamos soamente con himnos; así o Venceremos Nós, emblema sonoro da primavera aquela. Lembro a Fermín aporreado, sangrando no exterior do edificio, antes de ser introducido nunha daquelas "leiteiras", camiño da comisaría, logo do cárcere de Coruña. Fermín deixaría Santiago por Madrid, cando o estado de excepción de 1969, no que Bouza-Brey convencera aos esbirros que ían a polo fillo de que este estaba na Arxentina, país no que o noso amigo estivera de cativo; e cando viña a conto entoaba con vozarrón regularmente timbrado o mítico «Perón, Perón, qué grande sós, mi general, cuanto valés, Perón, Perón sós el primer trabajador, etc.». En Madrid Fermín licenciaríase en Filosofía (Pura, dicíase) e Psicoloxía encetando unha brillante carreira universitaria que habería de levalo, logo dun percorrido intenso, á cátedra de Opinión Pública da Facultade de Xornalismo. Nela acababa de xubilarse xusto antes de que a morte viñera seiturar a vida dun home especial; tanto que 
podo asegurar que poucas veces, como diante de Fermín, tiven a sensación de percibir o selo ou carimbo da intelectualidade en estado puro. Dono tamén dunha capacidade escritora ben sobranceira. Non é que o diga agora: teño escrito moito sobre Fermín. E por aí están as hemerotecas para non me deixar mentir: Diario de Ferrol, El Correo Gallego, El Urogallo, Leer, Gal(l)egos, etc. Sempre para lamentar o desinterese, o silencio brutal que caera sobre a obra literaria, en galego, de Fermín Bouza Álvarez. Como adoita acontecer cos que exercen fóra de Galicia de belixerantes nunha literatura endogámica, cos donos do negocio a exercer o negociado. ¿Cómo é posible que os catro libros galegos de Bouza Álvarez, dous de poesía, dúas novelas, ficaran no limbo, ninguneados cando non deostados? Non sorprenderá, xa que logo, que eses libros, publicados os catro entre 1980 e 1990, "expulsaran" a Fermín da nosa república das letras, sendo así que se negou a recuncar. Mesmo a recompilar a súa obra para Espiral Maior, malia a petición teimosa de Fernán Vello, el si sabedor do que valía esta. Certo que un deses libros, Labirinto de inverno (1990), o segundo de poesía de Bouza -o primeiro, O tempo na auga é de 1985-, foi Premio da Crítica Española; pero iso porque Basilio Losada, outro que si sabía, insistira en premiar ao Fermín. Faragullas para un autor soberbio, quen de escribir unha poesía sinxela mais dotada dun cerne ben intelectualizado á procura dese coñecemento que ten que estar de contino nas poéticas verdadeiras. E é que en poucos poetas como en Fermín Bouza Alvarez ética e estética están a se vencellar. $\mathrm{O}$ noso amigo, mais - para o caso- escritor de talento -son moi parcial do "Amicus Plato, sed magis amica veritas"- publicara tamén un par de novelas, Memoria do diaño (1980) e Longo voo do paxaro (1987). A primeira, achegamento realista (mais cun aquel de fantasía retranqueira), aos anos en que Santiago era unha cidade tan moza como nós mesmos. A segunda, recreación en clave de "cómic" das aventuras e desventuras dun paxaro chamado Roti. Un paxarolo que sobrevoa por riba dunha fábula onde a política xoga o seu rol. A política, esa preocupación constante do cidadán Fermín Bouza Álvarez, rexente dun blogue, "El voto con botas", ao que moitos concorríamos en tempo electoral para ver o que agoiraba o "perito en nubes baixas", como definín ao amigo que vén de marchar o sábado 29 de outubro do ano en curso, deixándonos cunha sensación

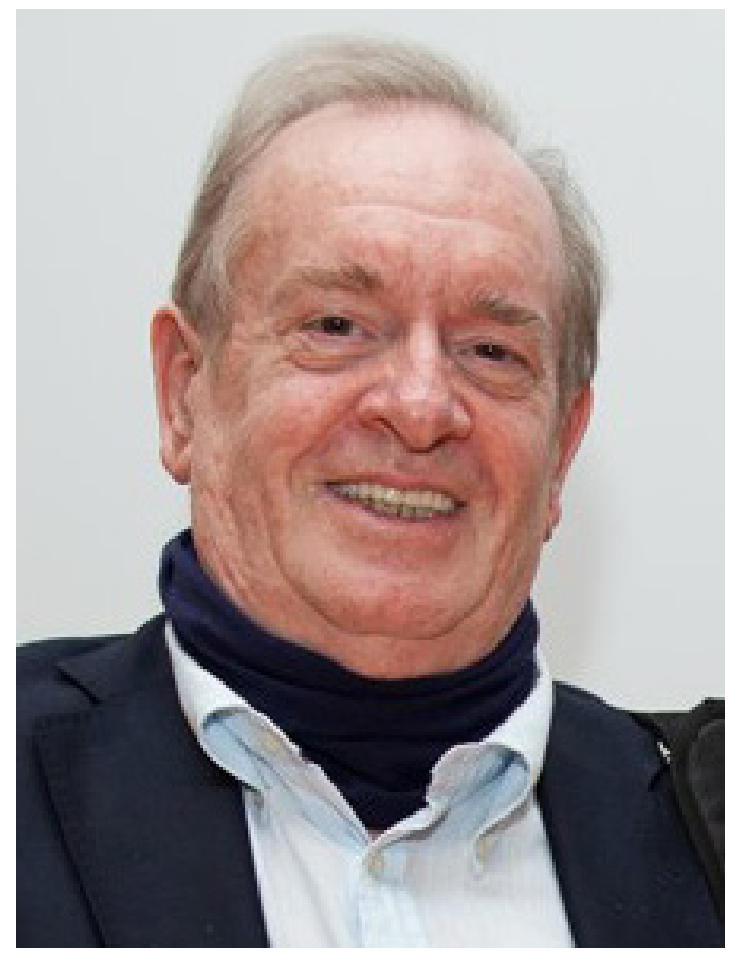

(fotografía: Fundación Paideia Galiza)

moi aceda e a seguridade de que moi poucos como el no tempo ruín abondo que nos toca vivir. Verbo da literatura galega (en español Fermín Bouza escribira unha rechamante novela de interiores, Las bodas secretas de Lilia, en 1991, de certa difusión na Feira de Francfort dese ano), ¿que dicir? Pedirlle, talvez, meirande agudeza visual, para que non se volvan repetir casos como este, de esquecementos tan extremos como inxustos. Polo demais, Fermín Bouza, home tan xeneroso como solidario (estivera no Grupo Bilbao nos seus comezos, e súa fora a idea de que as nosas tertulias morasen no Comercial, a unha carreiriña de can do seu domicilo chamberileiro da Calle Olid), tivo -ten- discípulos abondo, entre os que me inclúo, a partir do ensino peripatético que comigo exercera, como para deixar pegadas moi surtidas. Aínda que estas se chamen -níveasolgas, como a revista poética homónima-Olga, si- na que apareceu o último poema dado ao prelo por Fermín en vida:

\section{Entón}

Que o tempo chegue cando ti non esteas e que vaia atrás túa cando xa non te poida coller porque non paga nas fragas da memoria. 